\title{
PREVALENCE AND ASSOCIATED FACTORS OF IRRITABLE BOWEL SYNDROME AMONG HEALTHCARE PROFESSIONALS IN PRIMARY HEALTH CARE SETTING IN AL-MADINAH, SAUDI ARABIA
}

\author{
Hassan Yousef Taha* and Abdulaziz Al Johani \\ Joint Program of Family Medicine Postgraduate Studies. AL Madinah AL Munawara 42313, Saudi Arabia \\ Corresponding author: Hassan Yousef Taha \\ Email: Hasanytaha@gmail.com
}

\begin{abstract}
This cross-study aimed to determine the prevalence of IBS and its associated factors among 205 healthcare professionals in the primary health care centers in Al-Madinah City. Cluster sampling was used to select 16 primary health centers from the four regions of the city. A self-administered questionnaire was used to collect data about socio-demographics, Hospital Anxiety and Depression Scale (HADS), the Rome IV Diagnostic Questionnaire, dysphoria scale, and performance scale. Mean (SD) age of participant was 34.5 (6.6). Majority were nurses (40\%) and Saudi (93.7\%). The prevalence of IBS was $16 \%$. Factors associated with IBS in the univariate analysis were nationality $(p=0.023)$ anxiety $(p=0.010)$, depression $(p<0.001)$, performance $(p<0.001)$ and dysphoria $(p=0.003)$. In multivariate analysis, the significant predictor of IBS was depression $(a O R=1.3,95 \% \mathrm{Cl} 1.2-1.4, p<0.001)$. In conclusion, the prevalence of IBS among healthcare professionals in the current study was $16.1 \%$, with predominantly IBS-Constipation subtype. IBS was associated mainly with depression. Future intervention studies are recommended to establish possible causal inferences between psychological morbidities and quality of life domains for rectification on treatment aspects of IBS.
\end{abstract}

Keywords: irritable bowel syndrome, risk factors, depression, anxiety, quality of life, mental health

\section{INTRODUCTION}

Irritable Bowel Syndrome (IBS) is a common nonfatal functional gastrointestinal disorder that affects approximately $3-22 \%$ of the populations worldwide ${ }^{1-3}$. The prevalence of IBS in most western countries constituted 20\%, while in Asia the prevalence varied from $2.9 \%$ to $15.6 \%^{4}$. Its clinical manifestations, predominantly being altered bowel habits with abdominal pain or discomfort ${ }^{1}$ has impacted IBS sufferers work productivity, causing poor quality of life and escalated healthcare expenditures ${ }^{2}$.

The etiology of IBS remains unknown but psychological morbidities, social and biological attributes have been hypothesized to increase the risk of IBS disorders ${ }^{5}$. IBS has been affecting more women than men of younger aged groups ${ }^{2}$. Psychological morbidities like anxiety, depression and stress are known to amplify IBS disorders ${ }^{3,6}$. Jerndal and colleagues concluded that anxiety exacerbates symptoms of IBS and affect the quality of life. Few studies have also hypothesized significant associations between morbid depression and $\mathrm{IBS}^{8,9}$. While psychosocial attributes posed higher risks for IBS, results of quality of life (QOL) surveys showed that poor QOL scores, particularly in the sub-domains of daily functioning and dissatisfaction of health services has been associated with greater severity of IBS $3,10,11$.
Research in IBS has shown a commensurate increase within the past decade, emphasizing on specific groups of people across different countries. While prior studies explored IBS prevalence in nursing and medical students ${ }^{1,5,6,12}$, emerging research from Pakistan $^{13}$, China ${ }^{4}$, Turkey ${ }^{2}$ and Saudi Arabia ${ }^{1}$ has divert its attention to healthcare professionals. Unanticipated work demands, stressful work conditions and hectic lifestyles in patient management have been postulated to increase the risk of IBS incidence among healthcare professionals. This study aimed to explore the prevalence of IBS and its associated factors among healthcare professionals in Al-Madinah City, Saudi Arabia.

\section{METHODOLOGY}

\section{Setting and Population}

This cross-sectional descriptive study was conducted among 205 healthcare professionals in the primary health care centers in Al-Madinah city. Al-Madinah is located in the western part of the Kingdom of Saudi Arabia $400 \mathrm{~km}$ north of Mecca. There are 57 primary healthcare centers in the city. The city was divided into four geographical regions; north, south, east and west. Four centres were selected from each region randomly. Then, all health care workers in each centre were approached. The sample size was calculated to be 
196 based on expected prevalence of $15 \%$, power of $80 \%$, and accuracy level of 0.05 . To compensate for non-response and missing data, $10 \%$ was added for a final sample size to be 216 .

\section{Study Instruments}

A self-administered questionnaire was used to collect data. It consisted of three parts. The first part included questions on the sociodemographic information such as gender, age, marital status, nationality, years of service and type of occupation. The second part included the validated Hospital Anxiety and Depression Scale (HADS). It consists of 14 items: seven for anxiety (HADS-Anxiety) and seven for depression (HADS-Depression). It is answered using a 4-point Likert scale ranging from 0 (not present) to 3 (considerable). The higher score, the higher level of anxiety or depression ${ }^{1}$. The third part assessed the IBS by using the validated Rome IV Diagnostic Questionnaire to screen for functional gastrointestinal disorders (FGIDs) including irritable bowel syndrome ${ }^{14}$. It consists of 21 items. Items 1 to 6 are used to diagnose IBS and its types. Items 7 to 13 are used to assess the interference with performance and items 14 to 21 are used to assess dysphoria. IBS was defined according to Rome IV criteria as recurrent abdominal pain for at least once weekly during the past 3 months, associated with two or more of the following features (a) related to defecation at least $30 \%$ of occasions; and/or (b) onset associated with a change in frequency of stool at least 30\% of occasions; and/or (c) onset is associated with a change in form (appearance) of stool. Permission was obtained from The Rome Foundation to use this tool.

\section{Ethical Statement}

This study protocol was approved by the ethical committee of the Institutional Review Board in AlMadinah (Reference number: IRB-153). Objectives and benefits of the study were explained to the participants. Participants confidentiality and anonymity were assured. Signed consent was obtained from those who agreed to participate.

\section{Statistical Analysis}

Analysis was performed using Statistical Package for the Social Sciences (SPSS ${ }^{\circledR}$ ) (version 22.0, IBM,
Armonk, NY). Test of normality and internal consistency (Cronbach's alpha) were employed for the followings: Hospital Anxiety and Depression Scale, dysphoria and performance scales. Descriptive analysis was employed to obtain mean, SD for the continuous variables and to obtain frequency and percentage for the categorical variables. Chi square test was employed to assess association between IBS and categorical data where t-test was employed to assess association between the continuous and categorical variables. Multiple logistic regression analysis was conducted to determine the predictors of IBS. The accepted level of significance was set below $0.05(p<0.05)$.

\section{RESULTS}

\section{Descriptive Statistics}

A total of 205 participated in the study with response rate of $95 \%$. Mean (SD) age of participant was 34.5 (6.6) and age ranged from 22 to 63 years. The majority aged more than 30 years $(72.7 \%)$ and had served for more than 10 years (36.6\%). About half were male $(50.2 \%)$. Majority were nurses $(40 \%)$ and married $(76.6 \%)$. The vast majority were Saudi (93.7\%) (Table 1). Descriptive statistics and internal consistency (Cronbach' Alpha) of the continuous variables are shown in table 2.

Prevalence of Irritable Bowel Syndrome and Its Associated Factors:

The prevalence of IBS was $16 \%$ (33/205). Prevalence of subtypes of IBS are shown in table 3. Non-Saudi had higher prevalence of IBS than Saudi $(O R=3.7$, $95 \% \mathrm{Cl} 1.25-12.0)$. Those who had IBS showed higher score in anxiety $(11.4 \pm 3.2)$ and depression scale $(11.7 \pm 3.4)$ compared to those who had not IBS $(8.9$ $\pm 2.7)(6.3 \pm 2.4)$ respectively, $(p=0.010, p<0.001$ respectively). Performance was significantly lower (11.8 \pm 3.8$)$ among participants who had IBS in comparison to those who had not IBS $(11.8 \pm 3.8)$, $(p<0.001)$. Participants who had IBS showed higher score in dysphoria $(15.8 \pm 3.8)$ compared to those who had not IBS $(11.3 \pm 3.1),(p=0.003)$ (Table 4). In multivariate analysis, the significant predictor of IBS was depression score $(\mathrm{aOR}=1.3,95 \% \mathrm{Cl} 1.2-1.4)$. The total model was significant $(p<0.05)$ and explained $29 \%$ of the variability of the outcome (Table 5). 
Table 1: Sociodemographic Characteristics of The Participants

\begin{tabular}{lll}
\hline Variables & Frequency $(\mathbf{n})$ & Percent (\%) \\
\hline $\begin{array}{l}\text { Gender } \\
\text { Male }\end{array}$ & 103 & 50.2 \\
$\quad$ Female & 102 & 49.8 \\
Age $\quad$ & 56 & 27.3 \\
$\quad 30$ or less & 149 & 72.7 \\
$\quad>30$ & & \\
Year of service & 61 & 29.8 \\
$\quad$ 5 years & 69 & 33.7 \\
6-10 years & 75 & 36.6 \\
$\quad$ > 10 years & 192 & 93.7 \\
Nationality & 13 & 6.3 \\
$\quad$ Saudi & & \\
$\quad$ Non-Saudi & 48 & 23.4 \\
Marital status & 157 & 76.6 \\
$\quad$ Single & & \\
$\quad$ Married & 78 & 38.0 \\
Occupation & 45 & 22.0 \\
$\quad$ Medical doctor & 82 & 40.0 \\
$\quad$ Lab technician & &
\end{tabular}

Table 2: Descriptive statistics And Internal Consistency (Cronbach' Alpha) of the Continuous Variables in the Study

\begin{tabular}{llll}
\hline Variables & Mean & Sd & Cronbach' Alpha \\
\hline Anxiety score & 9.3 & 3.9 & 0.82 \\
Depression score & 7.2 & 3.5 & 0.87 \\
Performance & 12.6 & 4.5 & 0.86 \\
Dysphoria & 11.9 & 4.6 & 0.92 \\
\hline
\end{tabular}

Table 3: Prevalence of IBS subtypes among participants

\begin{tabular}{llll}
\hline IBS subtypes & $\mathbf{n}$ & \% of IBS cases & \% of total sample \\
\hline IBS-C & 23 & 69.7 & 11.2 \\
IBS-D & 5 & 15.2 & 2.4 \\
IBS-M & 4 & 12.1 & 2.0 \\
IBS_U & 1 & 3 & 0.5 \\
\hline
\end{tabular}

\section{DISCUSSION}

This study aimed to determine the prevalence and factors associated with IBS among primary healthcare professionals in Al-Madinah City, Saudi Arabia. The prevalence of IBS in this study was $16.1 \%$. The estimated prevalence rate of IBS was slightly higher than that found in Turkish $(13.5 \%)^{2}$, Saudi $(14.4 \%)^{1}$ and Korean $(15 \%)^{15}$ healthcare personnel, but relatively lower than that found in Pakistani healthcare professionals $(41 \%)^{13}$ and Libyan medical interns $(31.8 \%)^{5}$. In contrast to a survey conducted among nurses in Saudi Arabia found that IBS-Mixed to be more prevalent, the current study found that IBS-Constipation Dominant was the commonest subtype variety $(69.7 \%)^{1}$. Such findings could be attributed to variations in sample size, cultural differences in the studied populations or differences in local clinical practice guidelines to screen IBS.

Studies highlighting the associations between gender and IBS showed mixed variations. Most studies showed that women had higher odds than men to be affected with IBS $2,16-18$. However, a study from Pakistan found otherwise ${ }^{13}$. This study found that men had higher odds than women to be affected with IBS but this association was not statistically significant. Previous investigations hypothesized that IBS is an illness of the young and middle-aged groups, with its' incidence decreasing with older age ${ }^{19,20}$. However, the current study 
found no significant difference in IBS prevalence between the age groups. Tosun et al ${ }^{1}$ found similar consistencies. A notable finding in this study was that non-Saudis had higher odds of being affected with IBS as compared to Saudis. As majority of non-
Saudis are migrants, such findings could be attributed to food hypersensitivity, a maladaptive effect on the intake of different food items in a different geographical region influenced by cultural differences and eating habits ${ }^{5,21}$.

Table 4: Association between IBS and Study Variables in Univariate Analysis

\begin{tabular}{|c|c|c|c|c|}
\hline \multirow[t]{2}{*}{ Variables } & \multicolumn{2}{|c|}{ Irritable bowel syndrome } & \multirow[t]{2}{*}{ OR $(95 \% \mathrm{Cl})$} & \multirow[t]{2}{*}{$P$ value } \\
\hline & Yes n (\%) & No $n(\%)$ & & \\
\hline \multicolumn{5}{|l|}{ Gender } \\
\hline Male & $18(17.5)$ & $85(82.5)$ & $1.2(0.6-2.6)$ & 0.590 \\
\hline Female & $15(14.7)$ & $87(85.3)$ & & \\
\hline \multicolumn{5}{|l|}{ Age } \\
\hline 30 or less & $11(19.6)$ & $45(80.4)$ & $1.4(0.6-3.1)$ & 0.397 \\
\hline$>30$ & $22(14.8)$ & $127(85.2)$ & & \\
\hline \multicolumn{5}{|l|}{ Year of service } \\
\hline$\leq 5$ years & $9(14.8)$ & $52(85.2)$ & & \\
\hline $6-10$ years & $12(17.4)$ & $57(82.6)$ & & \\
\hline$>10$ years & $12(16.0)$ & $63(84.0)$ & & 0.920 \\
\hline \multicolumn{5}{|l|}{ Nationality } \\
\hline Saudi & $28(14.6)$ & $164(85.4)$ & & \\
\hline Non-Saudi & $5(38.5)$ & $8(61.5)$ & $3.7(1.25-12.0)$ & 0.023 \\
\hline \multicolumn{5}{|l|}{ Marital status } \\
\hline Single & $8(16.7)$ & $40(83.3)$ & $1.1(0.4-2.5)$ & 0.902 \\
\hline Married & $25(15.9)$ & $132(84.1)$ & & \\
\hline \multicolumn{5}{|l|}{ Occupation } \\
\hline Medical doctor & $15(19.2)$ & $63(80.8)$ & & \\
\hline Lab technician & $7(15.6)$ & $38(84.4)$ & & \\
\hline Nurse & $11(13.4)$ & $71(86.6)$ & & 0.602 \\
\hline \multicolumn{5}{|c|}{ Mean (SD) } \\
\hline Anxiety score & $11.4(3.2)$ & $8.9(2.7)$ & & 0.010 \\
\hline Depression score & $11.7(3.4)$ & $6.3(2.4)$ & & $<0.001$ \\
\hline Performance & $11.8(3.8)$ & $16.8(2.0)$ & & $<0.001$ \\
\hline Dysphoria & $15.8(3.8)$ & $11.3(3.1)$ & & 0.003 \\
\hline
\end{tabular}

Table 5: Factors Associated with IBS in Multivariate Analysis

\begin{tabular}{lllllll}
\hline Variables & B & S.E. & Wald & df & OR $(95 \%$ Cl) & P value \\
\hline Depression score & 0.270 & 0.049 & 30.295 & 1 & $1.3(1.2-1.4)$ & $<0.001$ \\
Constant & 4.039 & 0.541 & 55.700 & 1 & & \\
\hline
\end{tabular}

IBS individuals often suffer greater psychological morbidities and lower quality of life ${ }^{22,23}$. This study found a significantly higher interference of daily performance activities score among healthcare workers with IBS. Similar findings were found in previous studies in the general population ${ }^{24,25}$. Symptom manifestations among IBS sufferers, either solely or in combination of chronic or recurrent abdominal pain, diarrhea, constipation or distension may impact individuals daily activity ${ }^{26}$; thus, interrupting one's work performance with higher missed working days, decreased work productivity and greater health service utilization ${ }^{27-}$ 29. As most symptoms fluctuate over time and interventions being inaccurate to relieve discomfort immediately, previous studies showed high levels of dissatisfaction with treatment received ${ }^{30,31}$.
Consistent with these findings, the current study found a significantly higher dysphoria score among individuals with IBS.

Studies have postulated that psychological morbidities like anxiety and depression have led to the development of IBS ${ }^{2}$. Healthcare occupations posit high level of stressful situations due to work nature that demands high commitment to compete against time ${ }^{2,32-34}$. This study found that higher mean anxiety score significantly corroborated with IBS individuals. This finding was consistent with previous studies conducted among medical students and interns and healthcare professionals ${ }^{1,13,35,36}$. This study found that depression score was significantly higher among individuals with IBS. Similar findings were reported in previous studies 
conducted among healthcare professionals in other countries like Pakistan ${ }^{13}$ and Libya ${ }^{1}$, but inconsistent with a study conducted in $\mathrm{China}^{4}$. It could be postulated that psychological morbidities could be attributed to IBS when alteration in central nervous system (CNS) responses to psychological stressors cause colonic spasms, resulting in symptom manifestations of IBS ${ }^{37}$.

Certain limitations of the current study should be taken into consideration. First, the cross-sectional nature of the study could not establish causal relationships between IBS and the variables being studied. Second, the relatively small sample size limits the generalizability of the study findings. Third, the study utilized self-reported measures without using upper endoscopy and colonoscopy to exclude structural intestinal diseases to reach the diagnosis of IBS, thus overestimation of IBS prevalence and response bias is anticipated.

\section{CONCLUSION}

The prevalence of IBS among healthcare professionals in the current study was $16.1 \%$, with predominantly IBS-Constipation subtype. NonSaudis showed a significantly higher IBS prevalence. Anxiety, depression and quality of life showed significant associations with IBS in this sample. Future intervention studies are warranted to establish possible causal inferences between psychological morbidities and quality of life domains for rectification on treatment aspects of IBS.

\section{COMPETING INTERESTS}

The authors declare that they have no competing interests.

\section{Funding}

Not Applicable

\section{REFERENCES}

1. Ibrahim NK, Al-Bloushy RI, Sait SH, et al. Irritable bowel syndrome among nurses working in king Abdulaziz University Hospital, Jeddah, Saudi Arabia. Libyan J Med. 2016; 11: 30866.

2. Tosun 0 , Dabak $R$, Sargin $M$, et al. Frequency of irritable bowel syndrome among healthcare personnel. Gastroenterology Nursing. 2016; 39(3): 227-231.

3. Qureshi SR, Abdelaal AM, Janjua ZA, et al. Irritable bowel syndrome: A global challenge among medical students. Cureus. 2016; 8(8):e721.
4. Liu L, Xiao Q, Zhang $\mathrm{Y}$, et al. A crosssectional study of irritable bowel syndrome in nurses in China: prevalence and associated psychological and lifestyle factors. J Zhejiang Univ-Sci B (Biomed \& Biotechnol). 2014; 15(6):590-597.

5. Ibrahim NK, Battarjee WF, Almehmadi SA. Prevalence and predictors of irritable bowel syndrome among medical students and interns in King Abdulaziz University, Jeddah. Libyan J Med. 2013; 8:21287.

6. Dong YY, Zuo XL, Li CQ, et al. Prevalence of irritable bowel syndrome in Chinese college and university students assessed using Rome III criteria. World J Gastroenterol. 2010; 16:4221-4226.

7. Jerndal $P$, Rinqstrom $G$, Agerforz $P$, et al. Gastrointestinal-specific anxiety: an important factor for severity of $\mathrm{GI}$ symptoms and quality of life in IBS. Neurogastroenterol Motil. 2010; 22(6):646e179.

8. Nicholl BI, Halder SL, Macfarlane GJ, et al. Psychosocial risk markers for new onset irritable bowel syndrome - results of a large prospective population based study. Pain. 2008; 137(1):147-155.

9. Savas LS, White DL, Wieman M, et al. Irritable bowel syndrome and dyspepsia among women veterans: prevalence and association with psychological distress. Aliment Pharmacol Ther. 2009; 29(1):115125.

10. El-Serag HB. Impact of irritable bowel syndrome: prevalence and effect on healthrelated quality of life. Rev Gastroenterol Disord. 2003; 3:S3-11.

11. Huang WW, Zhou FS, Bushnell DM, et al. Cultural adaptation and application of the IBS-QOL in China: a disease-specific qualityof-life questionnaire. Qual Life Res. 2007; 16:991-96.

12. Okami Y, Kato T, Nin G, et al. Lifestyle and psychological factors related to irritable bowel syndrome in nursing and medical school students. J Gastroenterol. 2011; 46:1403-10.

13. Jafri W, Yakoob J, Jafri N, et al. Irritable bowel syndrome in healthcare professionals 
in Pakistan. Journal of Pakistan Medical Association. 2003; 53(9): 405.

14. Schmulson MJ, Drossman DA. What Is New in Rome IV. J Neurogastroenterol Motil. 2017;23(2):151-163

15. Koh SJ, KimM, Ohda Y, et al. Psychosocial stress in nurses with shift work schedule is associated with functional gastrointestinal disorders. J Neurogastroenterol Motil. 2014; 20: 516-522.

16. Kang JY. Systematic review; the influence of geography and ethnicity in IBS. Alimentary Pharmacology \& Therapeutics. 2005; 21: 663-676.

17. Drossman DA. The functional gastrointestinal disorders and the Rome III process. Gastroenterology. 2006; 130: 1377-1390.

18. Chang FY, Lu CL. Irritable bowel syndrome in the $21^{\text {st }}$ century: Perspectives from Asia or South-east Asia. Journal of Gastroenterology and Hepatology. 2007; 22:4-12.

19. Drossman DA, Sandler RS, McKee DC, et al. Bowel patterns among subjects not seeking healthcare. Use of a questionnaire to identify a population with bowel dysfunction. Gastroenterology. 1982; 83: 529-534.

20. Hobday DI, Aziz Q, Thacker N, et al. A study of the cortical processing of ano-rectal sensation using functional MRI. Brain. 2001; 124: 361-368.

21. Carroccio A, Brusca I, Mansueto P, et al. Fecal assays detect hypersensitivity to cow's milk protein and gluten in adults with irritable bowel syndrome. Clin Gastroenterol Hepatol. 2011; 9:965971.e3.

22. Drossman DA, Camilleri M, Mayer EA, et al. AGA technical review on irritable bowel syndrome. Gastroenterology. 2002; 123: 2108-2131.

23. Kanuri N, Cassell B, Bruce SE, et al. The impact of abuse and mood on bowel symptoms and health-related quality of life in irritable bowel syndrome (IBS). Neurogastroenterol Motil. 2016; 28(10): 1508-1517.
24. Hungin AP, Whorwell PJ, Tack J, et al. The prevalence, patterns and impact of irritable bowel syndrome: an international survey of 40,000 subjects. Aliment Pharmacol Ther. 2003; 17(5): 643-650.

25. Ballou SK, Keefer L. Multicultural considerations in the diagnosis and management of irritable bowel syndrome: a selective summary. Eur J Gastroenterol Hepatol. 2013; 25(10): 1127-1133.

26. Patrick DL, Drossman DA, Frederick IO, et al. Quality of Life in Persons with Irritable Bowel Syndrome: Development and Validation of a New Measure. Dig Dis Sci. 1998; 43(2): 400-411.

27. Shih YC, Barghout VE, Sandler RS, et al. Resource utilization associated with irritable bowel syndrome in the United States 1987-1997. Dig Dis Sci.2002; 47(8):1705-1715.

28. Dean BB, Aguilar D, Barghout $V$, et al. Impairment in work productivity and health-related quality of life in patients with IBS. Am J Manag Care. 2005, 11: S1726.

29. Pare P, Gray J, Lam S, et al. Health-related quality of life, work productivity, and health care resource utilization of subjects with irritable bowel syndrome: baseline results from LOGIC (Longitudinal Outcomes Study of Gastrointestinal Symptoms in Canada), a naturalistic study. Clin Ther. 2006; 28: 1726-35

30. Jamali R, Jamali A, Poorrahnama M, et al. Evaluation of health-related quality of life in irritable bowel syndrome patients. Health Qual Life Outcomes. 2012; 10(1):12.

31. Canavan C, West J, Card T. Change in quality of life for patients with irritable bowel syndrome following Referral to a gastroenterologist: A cohort study. Plos One. 2015; 10(10): e0139389.

32. Familoni OB. An overview of stress in medical practice. African Health Sciences. 2008; 8: 6-7.

33. Gregov L, Kovacevic A, Sliskovic A. Stress among Croatian physicians: comparison between physicians working in emergency medical services and health centers - pilot 
study. Croatian Medical Journal. 2011; 52: 8-15.

34. Kemper K, Bulla S, Krueger D, et al. Nurses experiences, expectations and preferences for mind-body practices to reduce stress. BMC Complement Altern Med. 2011; 11: 26.

35. Sugaya N, Nomura S. Relationship between cognitive appraisals of symptoms and negative mood for subtypes of irritable bowel syndrome. Biopsychosoc Med. 2008; 2:9.

36. Naeem SS, Siddiqui EU, Kazi AN, et al. Prevalence and factors associated with irritable bowel syndrome among medical students of Karachi, Pakistan: a crosssectional study. BMC Res Notes. 2012; 5: 255.

37. Tan YM, Goh KL, Muhidayah R, et al. Prevalence of irritable bowel syndrome in young adult Malaysians: A survey among medical students. J Gastroenterol Hepatol. 2003; 18: 1412-1416. 